\title{
Genetic Testing for Breast Cancer Patients: Is Everyone Who Needs a Test Getting a Test?
}

\author{
Danielle R. Heller, MD, MHS ${ }^{1}$, Ann-Kristin U. Friedrich, MD', and Brigid K. Killelea, MD, MPH, FACS ${ }^{2}$ \\ ${ }^{1}$ Section of Surgical Oncology, Department of Surgery, Yale University School of Medicine, New Haven, CT; ${ }^{2}$ Director of \\ Breast Surgery, St. Vincent's Medical Center, Hartford HealthCare, Bridgeport, CT
}

Genetic testing and counseling are important elements of comprehensive breast cancer care. Both positive and negative results have implications for patients diagnosed with cancer, unaffected mutation carriers, and untested family members. It is currently estimated that approximately $5-10 \%$ of all breast cancers are due to genetic mutations. ${ }^{1,2}$ Because breast cancer is the most common malignancy among women in the United States, with yearly incidence exceeding 250,000 cases, this proportion of gene-based breast cancer is significant. ${ }^{1}$

Genetic analysis for many breast patients has evolved from testing for BRCA 1 and 2 mutations alone to multigene panel testing, depending on personal and family history. At the present time, oncogenic mutations in $\mathrm{CDH}-$ 1, PTEN, ATM, PALB2, and many others are not uncommonly diagnosed in breast patients referred for testing. For those with breast cancer, results of expanded genetic testing may influence both medical and surgical oncologic treatment pathways. For example, recommendations regarding immunotherapy, radiotherapy, and the extent of surgical resection may be altered by the presence of certain mutations. For unaffected carriers who are at higher risk of developing aggressive cancers at a younger age than the general population, genetic counseling may facilitate decision-making around enhanced screening/surveillance, chemoprevention, prophylactic mastectomy, and family planning. Because these strategies

(C) Society of Surgical Oncology 2020

First Received: 8 September 2020

Accepted: 12 September 2020;

Published Online: 15 October 2020

B. K. Killelea, MD, MPH, FACS

e-mail: brigid.killelea@hhchealth.org themselves confer health risks, expert counseling focused on balancing the risks and benefits of screening and treatment are key to utilize appropriately the knowledge gained from testing.

In the current retrospective, single-institutional study by Alberty-Oller and colleagues, this opportunity to apply information regarding gene status was missed in over a quarter of newly diagnosed breast cancer patients deemed eligible for testing by NCCN standards. ${ }^{3}$ This finding is particularly striking given the setting of their study-a comprehensive breast cancer center with ample testing resources and well-established genetics referral practices. The authors identified several associated factors, including patient noncompliance, older age, non-Ashkenazi Jewish ethnicity, and missed family history on the part of physicians. They concluded that genetic testing should be offered broadly and systematically according to current NCCN guidelines and that compliance with genetic counseling should be closely monitored.

Others have called for more inclusive testing criteria, based on recent studies which suggest that the current testing criteria may be too stringent, thus losing the opportunity to intervene before cancer is diagnosed. In a 2018 comparison of pathogenic/likely pathogenic mutations found in gene-tested Medicare patients who did and did not meet the insurance policy's testing criteria, Yang and colleagues found that detection rates among the groups were nearly identical. ${ }^{4}$ They concluded that had patients not meeting criteria foregone testing, a significant number of clinically actionable mutations would have been missed. Similarly, in a 2019 multicenter study comparing newly identified mutations among patients who did and did not meet NCCN testing criteria, Beitsch and colleagues also found comparable detection rates. ${ }^{5}$ They recommended that the guidelines be essentially eliminated and that all 
patients with new diagnoses of breast cancer be tested. The 2019 consensus guideline put forth by the ASBrS supports this catch-all approach. ${ }^{6}$ Others have advocated casting an even wider net; Dr. Mary Claire King, who discovered BRCA 1, has advocated for universal BRCA testing for all women starting around age $30 .^{7}$

Certainly, there are important potential downsides to broad genetic testing. While the cost of testing has decreased significantly in recent years, it remains a barrier in our current healthcare climate, particularly for the underinsured and uninsured. Certified genetic counselors are already in short supply nationally; adding to the demand for testing without a commensurate increase in the number of counselors may leave patients with results that they cannot use without appropriate guidance. Also, some of the data are clinically unactionable; as the number of genes tested increases, so does detection of variants of uncertain significance (VUS). ${ }^{8}$ Knowledge of such variants without timely expert counseling may bring undue stress and anxiety to patients and family members. Ultimately, this may lead to unwarranted chemo- or surgical prevention and overtreatment of indolent cancers.

Dr. Alberty-Oller and colleagues should be commended for their transparency regarding institutional adherence to testing guidelines and for raising awareness about how patients might fall through the cracks. Their data highlight the importance of education and accountability on the part of patients and physicians in ensuring that eligible individuals are referred and tested. Testing all patients who meet NCCN criteria is a good start, as debate continues about how wide to cast the net. Closing the testing gap without overshooting appears to be the next issue to resolve.
DISCLOSURES Brigid Killelea - Advisory Board, Genentech; Royalties, Up to Date.

\section{REFERENCES}

1. American Cancer Society: Breast Cancer Facts \& Figures 2017-2018. American Cancer Society, Atlanta, GA. 2017. Available at: https://www.cancer.org/content/dam/cancer-org/rese $\mathrm{arch} /$ cancer-facts-and-statistics/breast-cancer-facts-and-figures/bre ast-cancer-facts-and-figures-2017-2018.pdf. Accessed Sept 2020.

2. Norquist BM, Harrell MI, Brady MF, et al. Inherited mutations in women with ovarian carcinoma. JAMA Oncol. 2016;2(4):482-90.

3. Alberty-Oller JWS, Santos A, Pisapati K, Ru M, Weltz C, Schmidt $\mathrm{H}$, Port E. Adherence to NCCN guidelines for genetic testing in breast cancer patients: who are we missing? Ann Surg Oncol. 2020 (In press).

4. Yang S, Axilbund JE, O'Leary E, et al. Underdiagnosis of hereditary breast and ovarian cancer in Medicare patients: genetic testing criteria miss the mark. Ann Surg Oncol. 2018;25(10):2925-31.

5. Beitsch PD, Whitworth PW, Hughes K, et al. Underdiagnosis of hereditary breast cancer: are genetic testing guidelines a tool or an obstacle? J Clin Oncol. 2019;37(6):453-60.

6. American Society of Breast Surgeons: Consensus Guideline on Genetic Testing for Hereditary Breast Cancer. Available at: https:// www.breastsurgeons.org/docs/statements/Consensus-Guideline-o n-Genetic-Testing-for-Hereditary-Breast-Cancer.pdf. Accessed September 2020.

7. King M, Levy-Lahad E, Lahad A. Population-based screening for BRCA1 and BRCA2: 2014 Lasker Award. JAMA. 2014;312(11):1091-2.

8. Copur MS, Jonglertham P, Zusag T. Should all patients with a diagnosis of breast cancer undergo expanded panel testing? J Clin Oncol. 2019;37(24):2175-6.

Publisher's Note Springer Nature remains neutral with regard to jurisdictional claims in published maps and institutional affiliations. 